\title{
A Literature Review on the Study of Chattel Pledge Supervision in Logistics and Supply Chain Finance of China
}

\author{
Aimin Deng ${ }^{1,2}$, Xiang Lu ${ }^{1,2}$ \\ ${ }^{1}$ School of Economics and Trade, Hunan University, Changsha, China \\ ${ }^{2}$ Institute of Transportation and Logistics, Hunan University, Changsha, China \\ Email: aimindeng@hnu.edu.cn,970615059@qq.com
}

How to cite this paper: Deng, A. M., \& Lu, X. (2017). A Literature Review on the Study of Chattel Pledge Supervision in Logistics and Supply Chain Finance of China. Journal of Financial Risk Management, 6, 93100

https://doi.org/10.4236/jfrm.2017.62008

Received: March 11, 2017

Accepted: May 13, 2017

Published: May 16, 2017

Copyright (c) 2017 by authors and Scientific Research Publishing Inc. This work is licensed under the Creative Commons Attribution International License (CC BY 4.0).

http://creativecommons.org/licenses/by/4.0/

\begin{abstract}
Chattel pledge supervision, as a fast-growing emerging supply chain finance business model, has been got a lot of attention by the banks and other finance institutions, logistics enterprises and small and medium enterprises (SMEs), and it has become a good way to solve the financing difficulties of SMEs, to reduce the rate of non-performing loans of banks and other finance institutions and to expand the business of logistics companies; it has a broad prospect. This paper summarizes the existing literatures researched on the chattel pledge supervision, and it will provide reference for further study.
\end{abstract}

\section{Keywords}

Chattel Pledge Supervision, Logistics and Supply Chain Finance, Small and Medium Enterprises

\section{Introduction}

Chattel pledge supervision, also known as chattel pledge loans or chattel pledge financing (Shan, 2003; Yang et al., 2011), is a supply chain finance innovation business model, proposed by the logistics enterprises and banks and other financial institutions together for the loans of small and medium enterprises (SMEs) to provide value-added services. Pfohl \& Gomm (2009) defined chattel pledge supervision as the concept of business model proposed by logistics enterprises, which belongs to the category of supply chain finance. They thought supply chain finance and logistics finance are basically synonymous.

\section{Comprehensive Review}

Domestic and foreign scholars have studied the development of supply chain 
finance business, and summarized a lot of theoretical literature. Koch (1948), Dunham (1949), Birnbaum (1948) summed up the legal atmosphere, business model, warehousing, monitoring methods and processes of logistics finance business before the 1950s. Eisenstadt (1966) and Guttentag (1957) introduced the business model, control methods and advantages and disadvantages of the supply chain finance business in the 1950s and 1960s. Miller (1982) elaborated the new characteristics of the logistics finance business model during the reform of the 1970s and 1980s, and many of views had enlightened the development of the business under the present logistics and financial integration innovation. Lacroix and Varangis (1996) contrasted the logistics and financial business of the United States and developing countries, and argued that the integration and innovation of logistics finance at this stage was of great importance in transforming developing countries, and they specifically introduced the relevant business model and promote the development of specific business measures. Poe (1998) described an important realistic model in the logistics finance business, this was based on asset-based financing, which pointed out that inventory and accounts receivable were the main concerns collaterals of asset-based financing operations business. So all of the wholesalers, retailers and distributors are the objects of financing. Rutberg (2002) introduced the main features of the logistics finance model with UPS as an example. Fenmore (2004) further analyzed an emerging logistics finance business, which called the purchase-order financing. In domestic, Chen (1987) firstly proposed the concept of the establishment of material banks. Luo \& Zhu (2002) proposed to promote the pledge loans business of financing mode to boost the SMEs growing, they believed that the new business mode was a comprehensive third-party logistics service platform, which it was not only a new bridge of cooperation between banks and enterprises, but also could help SMEs to solve the financing problems, and could effectively integrate into the supply chain system of small and medium-sized enterprises to provide efficient services of the third party logistics. Feng (2007) identified two types of basic business models of inventory financing in China, that were warehouse pledge financing and inventory pledge financing business. Over the past decade, with the SMEs facing the development bottleneck, in order to alleviate the financing difficulties of SMEs, combining with international and domestic actual situation, chattel pledge have become the most important way of property guarantee financing because of their advantages of transferable possession and effective guarantee of the safety and completeness of collateral, but the property guarantee that inventory, accounts receivable and intellectual property rights were the most used movable pledge collateral (People's Bank of China Tianjin Branch Task Force \& Wu, 2009). Deng \& Chen (2017), they took the financing advantage of supply chain finance and designed the model of receivables financing of SMEs and used the Stackelberg model to infer the optimal pricing and the optimal profit of the bank and the small and medium-sized logistics enterprises.

The authors of the paper believe that chattel pledge financing has the advan- 
tages of flexibility and security, its development prospects are broader, and it will be accepted and understood by more and more financial institutions and SMEs.

$<$ Chattel pledge supervision service specification (approval draft) $>$ defined the chattel pledge supervision as: "The pledged person is pledged the lawful possession to the pledgee as a guarantee for repayment of the debt, and the supervisor accepts the entrustment of the pledgee, and within a certain period of time replace the pledgee to posses and manage the material." The author think that chattel pledge supervision as a supply chain finance business model, mainly highlight the supervision of this behavior, while the chattel supervision or chattel supervision loans highlight the purpose of the guarantee. Although there is a difference between the two modes, but there is no substantial difference in business content. Ding et al. (2014) thought that chattel pledge supervision is a financial innovation model in the supply chain from the perspective of logistics companies, although not standardized and rigorous, but still use the term, because: Firstly, from the historical point view that the business model in domestic was promoted to create by the logistics enterprises, the traces of the natural role of positioning was more heavy. Secondly, from the practical point view that SMEs, banks and other finance institutions and logistics enterprises need to sign $<$ chattel pledge supervision and cooperation agreement $>$ to agree on the rights and obligations of the tripartite agreement. Thirdly, from the introduction of industry standards that the Ministry of Commerce on March 25, 2013, issued a $<$ request for <chattel pledge supervision service standards (draft) $>$ and other two industry standards advice>, chattel pledge supervision will become industry normative terminology. Zhou (2012) believed that chattel pledge supervision refers to the customer enterprise (pledged person) with its legal possession of finished products, semi-finished products, raw materials and other movable property pledge to banks and other finance institutions (pledge) as to the pledgee credit financing guarantee, a third party (usually a logistics company) accepts the entrustment authority of the pledgee to supervise the material in accordance with the pledge agreement between the pledgee and the pledgee, and also provides the logistics service to the pledgor in accordance with the agreement with the pledgor. Cong (2015) defined the chattel pledge supervision which from the perspective of the actual situation of its business as the pledged person was pledged to the pledgee with its legally occupied movable property, and the pledgee provides commitment of credit financing to the pledge. The custodian accepts the business model of the pledgee's custody of the pledge in the pledge period. It can be seen that although scholars have different views on the meaning of chattel pledge supervision, but the difference is not significant. Therefore, it is generally believed that chattel pledge supervision was defined as borrowers (small and medium-sized enterprises) that entrust their professional materials, semi-finished products and inventories to banks and other finance institutions in order to obtain the loans funds and the finance institutions, in order to achieve the purpose of security loans, entrust the professional logistics enterprises to supervise the movable property which the SME pledged. 
At present, the existing literature on chattel pledge supervision research mainly studying from two aspects, one is the relevant legal attribute of movable property pledge supervision, and the other is the risk prevention problem in chattel pledge supervision.

As a new type of security, the chattel pledge supervision which the main body is the composition of the legal relationship between the participants. Ding \& Han (2014) thought that included four main body, that are the SMEs which need financing, banks and other finance institutions, the logistics enterprises which providing regulatory services, the fourth party warehouse (supervision and warehousing separation occurs). Fu (2011) took the entrusted relationship of chattel pledge supervision as the starting point, split the custody responsibility, combine the guarantee attribute of the material with the logistics company's own function, and according to the different business model, from simple to complex, from single to comprehensive, to explore the logistics company's regulatory responsibility. Gao (2012), according to the business practice, concluded three types of pledge supervision mode, and focused on the legitimacy and inherent defects of output pledge supervision, and analyzed the obligations and responsibilities of logistics enterprises. Sun (2014), through analyzing the relevant cases, thought that under the chattel pledge supervision contract, the supervisor of the material should undertake the audit, custody, supervision and other obligations. However, how to correctly understand the legal relationship of chattel pledge supervision, how to judge the responsibility of the supervisor for finance institutions, how to determine the validity of the pledge are the urgent problems to be solved. Wu (2015), according to the relevant trial practice involved in the case of chattel pledge supervision of the contract cases, took from the manufacturer's silver business model, and made recommendations through the chattel pledge supervision in the contract and the legal effect of the legal analysis. Zhang \& Wang (2015) made the definition on the concept of chattel pledge, on the legal relationship of chattel pledge supervision in chattel, on the custodian of the quality of the possession of the leadership of the formation of legal analysis, in order to identify chattel pledge possession of goods. Wang (2016) through analyzed the chattel pledge supervision business legal dilemma and demonstration to the national standard "guarantee of inventory third party management practices" as an opportunity to clear the inventory "supervision" "monitoring" two models of the rights of the relevant parties obligations and responsibilities, the use of "common possession" theory to reconstruct the existence of multi - level possession of movable property under the conditions of the effectiveness of the delivery. Wang (2016) made the analysis and demonstration of the legal dilemma of chattel pledge supervision business, took an opportunity as the national standard <to ensure the implementation of third-party management of inventory norms $>$, clearly the two modes of the relevant party's rights and obligations and responsibilities of guarantee the inventory supervision and monitoring, and using the "common possession" theory to reconstruct the validity of the delivery of the pledge of movable property under the multi - storey situation. 
Chattel pledge supervision as a supply chain finance business of a new business model has many advantages, becoming an important way to solve the financing difficulties of SMEs, but cause of the instability economic form, and this model is still in the domestic exploration stage and is not yet mature in theoretical research and practice; In particular, this business model related to the law, information security and management systems and other issues, making the parties face greater risk, so the parties must be responsible for the prevention and management of the risks faced by chattels. "China Storage and Transportation" journalists (2013) summarized the 10 major risk characteristics common to chattel pledge in recent years through the credit crisis in the Yangtze River Delta steel trade industry in 2012. Chen \& Song (2006) focused on the risk of the pledge guarantee business of commercial banks in China, and put forward the corresponding regulatory suggestions and counter measures. Zhang \& Wang (2012) thought the logistics enterprises should be carefully selected collateral, strengthen market information collection and collation, strengthen internal management, standardize the operation process and strict audit of corporate credit and other measures to reduce the risk. Wang \& Long (2012) proposed to make using of information technology to build advanced features of the risk monitoring platform, making the traditional banking, regulatory companies and enterprises tripartite serial regulatory model into a parallel regulatory model, so that banks can be real-time chattel pledge risk monitoring. Jiao (2010) build a practical dynamic monitoring system on the basis of a brief introduction of the chattel pledge loan business, and introduced using the Internet of things technology in the system in detail. Xu (2010) analyzed the chattel pledge loan business characterized by inventory pledge, which has been carried out in many commercial banks, he believed that the current provisions lacking practical operation, and thus the problem of regulatory failure of the material has been the difficulties faced by financial practitioners, he thought that using the Internet of things to control chattel pledge risk, to solve the problem of custody of movable property pledge. Pu and Tao (2013) analyzed the relevant processes and links through the actual cause of chattel pledge supervision, and from the aspects of logistics financial business of enterprise choice, prevention of major risk points and disposal of special problems to explore the provision of logistics finance business risk controlling strategy. Zhou (2010) thought the chattel in the process of custody supervision, because of the pledge rate with the market price fluctuations and then changing the formation of pledge risk, so, he proposed a replenishment strategy based on the Wiener process, and through a case study show the rationality of the strategy. Cong (2015) put forward the logistics enterprises to establish chattel pledge supervision and control of legal risk prevention and the long-term mechanism by explaining the meaning of movable property pledge supervision and its legal relationship, and the legal risks faced by logistics enterprises, then he analyzed the legal risk identification and prevention or control measures of movable property pledge supervision in logistics enterprises. Yang and Gao (2016) through made the risk assessment of chattel pledge super- 
vision business, used the triangular fuzzy number and analytic hierarchy process to determine the weight of the evaluation index, it can effectively avoid the analytic hierarchy process in the subjective judgments and preferences, the results show that the method of determining the weight of triangular fuzzy number can effectively evaluate the risk of chattel mortgage supervision business, and provide a new way and decision method for finance institution to evaluate the risk of financing business. Deng and Chen (2017) researched the online supply chain finance credit risk of Asymmetric Information, they thought the Asymmetric Information is the main reason for causing online SCF credit risks; they also proposed the main solutions for the credit risks, including standardization of online supply chain financial processes, establishing credit risk evaluation system using big data etc.

\section{Conclusion}

Chattel pledge supervision, as a fast-growing emerging supply chain finance business model, has been got a lot of attention by the banks and other finance institutions, logistics enterprises and SMEs, and has become a good way to solve the financing difficulties of SMEs, to reduce non-performing rate of banks and other finance institutions and to expand business of logistics companies. It has a broad prospect. At the same time, we should also see the business model in China is still in the exploratory stage, and the relevant theory and practice is not yet mature, and its model involves the relevant legal attributes, information security and management system and other issues, making the parties face various risks, for example, how to understand the relevant legal relationship in the supervision of chattel pledge, how to effectively control the risk and improve the credit system, etc. Future research should pay more attention to these aspects.

\section{Acknowledgements}

Like other research, this study is also supported by a number of projects from China and Germany. For example, the National Science Foundation of China (71172194); 2015 Hunan's University Collaborative Innovation Project (No. 2015/69); German BMBF(No.APR10/810); Social Science Funds Project in $\mathrm{Hu}$ nan Province (No. 2012ZDB13); Hunan international cooperation projects (No. 2010WK3041); Chongqing Major Social Science Foundation (No. 2004ZD03); The International Cooperation Project of Science and Technology Department of Hunan Province (No. 2010WK3041).

\section{References}

Birnbaum, H. F. (1948). Form and Substance in Field Warehousing. Law \& Contemporary Problems, 13, 579-592. https://doi.org/10.2307/1189929

Chen, D., \& Song, X. (2006). On the Risk of Chattel Guarantee of Commercial Banks in China .Journal of Economic Research, No. 21, 119-121.

Chen, H. (1987). On the Material Bank's Vision. China Industrial Economy, No. 3, 75-76.

China Storage and Transportation Journalists (2013). Focus on Pledge to Monitor 10 
Major Risks. China Storage and Transportation, No. 8, 44-46.

Cong, Y. (2015). Research on Legal Risk of Chattel Pledge Supervision Based on Logistics Enterprises. Logistics Technology, 34, 60-63.

Deng, A., \& Chen, R. (2017). A Research on the Pricing of Receivables Financing for Small and Medium-Sized Logistics Enterprises Based on Supply Chain Finance. World Journal of Research and Review, 4, 22-26.

Deng, A., \& Chen, Z. (2017). Managing Online Supply Chain finance Credit Risk of "Asymmetric Information". World Journal of Research and Review, 4, 29-32.

Ding, L., \& Han, W. (2014). National Property of Chattel Pledge Supervision Business. China Circulation Economics, 28, 98-104.

Dunham, A. (1949). Inventory and Accounts Receivable Financing. Harvard Law Review, 62, 588-615. https://doi.org/10.2307/1336024

Eisenstadt, M. (1966). A Finance Company's Approach to Warehouse Receipt Loans (pp. 661-670). New York Certified Public Accountant 36.

Feng, G. (2007). Analysis of Logistics Financial Business Innovation. Forecast, 26, 49-54.

Fenmore, E. (2004). Making Purchase-Order Financing Work for You. Secured Lender (Mar/Apr).

Fu, X. (2011). Analysis on the Risk, Prevention and Control and Decentralization of Movable Property Pledge Supervision Business. China Storage and Transportation, No, 5, 76-79.

Fu, X. (2011). Study on the Pledge of Movable Property (8) Discussion on the Responsibility of Movable Property Pledge. China Storage and Transportation, No. 8, 89-93.

Gao, W. (2012). Performance Analysis of Pledge Supervision Business in Logistics Enterprises. Chinese Journal of Maritime Law, No. 1, 44-51.

Guttentag, J. (1957). Pledge Warehousing. The Journal of Finance, 12, 438-450. https://doi.org/10.1111/j.1540-6261.1957.tb04158.x

Jiao, F. (2010). Application of Internet of Things Technology in Dynamic Supervision System of Chattel Pledge. Enterprise Technology Development: Academic Edition, 29, 13-15.

Koch, A. R. (1948). Economic Aspects of Inventory and Receivables Financing. Law \& Contemporary Problems, 13, 566-578. https://doi.org/10.2307/1189928

Lacroix, R., \& Varangis, P. (1996). Using Warehouse Receipts in Developing and Transition Economies. Finance \& Development.

Luo, Q., Zhu, D., \& Chen, B. (2002). Third-Party Logistics Service Innovation: Financing Warehouse and Its Operation Mode. China Circulation Economics, 16, 11-14.

Miller, R. A. (1982). Mas Consultant's Role Asset-Based Financing. The CPA Journal, 52, 24-29.

People's Bank of China Tianjin Branch Task Force and Wu, P. (2009). Chattel Pledge: An Effective Way to Alleviate the Financing Difficulties of Small and Medium Enterprises. China Finance, No. 4, 46-48.

Pfohl, H. C., \& Gomm, M. (2009). Supply Chain Finance: Optimizing Financial Flows in Supply Chains. Logistics Research, 1, 149-161. https://doi.org/10.1007/s12159-009-0020-y

Poe, T. R. (1998). Subjective Judgments and the Asset-Based Lender. Commercial lending Review, 13, 67-70.

Pu, Z., \& Tao, J. (2013). Research on Logistics Financial Risk and Its Avoidance-A Case Study of Chattel Pledge Supervision. Logistics Technology, 32, 70-72. 
Rutberg, S. (2002). Financing the Supply Chain by Piggy-Backing on the Massive Distribution Clout of United Parcel Service. Secured Lender.

Shan, W. (2003). On the Chattel Pledge Loan Method. Credit Information, 21, 64- 65.

Sun, C., \& Jing, G. (2014). Obligation and Responsibility of Supervisors in Movable Pledge. People's Justice, No. 10, 78-82.

Wang, J. (2016). Study on Legal Dilemma and Path Choice of Chattel Pledge Supervision Business. Journal of Guangxi Administrative Cadre Institute of Politics and Law, 25, 29-37.

Wang, J., \& Long, Y. (2012). Study on the New Model of Movable Custody Risk Regulation in Commercial Banks. Hainan Finance, No. 6, 56-58.

Wu, L. (2015). Application of Movable Property Pledge Supervision in Bank Business. Application of Law, No. 3, 112-116.

$\mathrm{Xu}, \mathrm{H}$. (2010). Study on the Regulation of Chattel Pledge Based on Internet of Things. Journal of Modern Trade and Industry, No. 24, 327-328.

Yang, J., Yang, R., \& Meng, X. (2011). Discussion on Some Problems of Financing Model of Chattel Pledge. Economist, No. 8, 36-42.

Yang, Y., \& Gao, J. (2016). Study on Fuzzy Comprehensive Evaluation of Risk of Movable Pledge Financing Business Model Based on TFN-AHP. Computer \& Communication, No. 32.

Zhang, J., \& Wang, Y. (2012). Study on Risk Types and Precautions in Pledge Management of Logistics Enterprises. Reform and Strategy, 28, 195-198.

Zhang, X., \& Wang, Y. (2015). The Pledge of Movables Pledge in Legal Interpretation. China Chizi News, No. 6.

Zhou, D. (2010). Study on Replenishment Strategy Based on Wiener Process. Logistics Science and Technology, 33, 84-86.

Zhou, J., \& Li, S. (2012). A Legal Analysis of the Acts of Chattel Pledge Supervision. Journal of Law and Society, No. 23, 206-208.

Submit or recommend next manuscript to SCIRP and we will provide best service for you:

Accepting pre-submission inquiries through Email, Facebook, LinkedIn, Twitter, etc. A wide selection of journals (inclusive of 9 subjects, more than 200 journals)

Providing 24-hour high-quality service

User-friendly online submission system

Fair and swift peer-review system

Efficient typesetting and proofreading procedure

Display of the result of downloads and visits, as well as the number of cited articles

Maximum dissemination of your research work

Submit your manuscript at: http://papersubmission.scirp.org/

Or contact jfrm@scirp.org 